on her cheek following the baby's bent right arm. This kind of 'mirroring' of posture has been shown by video recordings to be a constant repetitive feature of mother-baby interactions. It is not, as might be thought, the baby imitating the mother; research shows that it is always initiated by the baby and then imitated by the mother. It is as if mothers are saying to these strange beings from outer space. "Look! there is sentient life on earth, it is friendly and you can influence it." Bables deprived of this interaction not only grow up physically and mentally handicapped, they often die.

The initial focal point is the mother's face. She is drawn in clearly and the features emphasised by the darkness of hair and dress, and the warm flesh tints. The open front of the dress and the light line of the wrist lead the eye immediately towards the baby, following her intent gaze. The baby's face forms the secondary focus. Much more lightly drawn, the obscuring transparency of the net curtain provides a convincing artistic reason for this and ensures there is no competition as the eye travels comfortably to and fro between the faces. The soft indistinctness draws us into the pleasure of sleep and gives the observer an instant of repose after the watchfulness of being with the mother. I feel that the subtle tertiary focus is the key to deeper feeling. Look how the eye automatically slides either along the base of the triangle, or down the straight line of the mother's back and arm, or down the curve of the curtain with its pink ribbons. In the lower left corner we rest on the tense right hand a moment. Perhaps the mother has only just pulled that pretty net around, caught in that lovely moment when you think the baby has finally dropped off and can relax almost completely. Almost - but not quite! Never. ever, quite completely relaxed again.

Elinor Kapp, Consultant Psychiatrist, Gwent Community Health NHS Trust, Child and Adolescent Mental Health Service, St Cadoc's Hospital, Lodge Road, Caerleon. Gwent NP6 1XQ

\title{
Writing an introductory handbook for trainees
}

\author{
Richard C. Barnes and Stephen M. Earnshaw
}

\begin{abstract}
'Induction days' are becoming more popular for trainees and are a useful way of communicating important local information to the now intake. The authors feel that a handbook given out during the induction can serve as an aide-memoire, and have provided a suggested layout which they themselves have used in preparing several such books.
\end{abstract}

The first few days in a new job are often difficult for trainees, and even more so if they are 'virgin' psychiatrists. An unfamiliar hospital, which may be large and disorientating, presents an additional challenge to clinical duties, and the experience of change is one most trainees have to face at least twice a year. Induction days are a useful step (Slatford, 1994) but often present a great deal of information in a short time, and focus on general rather than specifically local issues. Providing some form of written information can complement the induction process.

In an increasing number of units, introductory handbooks are becoming popular to provide guidance for those early days. We both have experience in writing such handbooks - and in the reading of other people's. We have found the 
following a useful format, based on our having worked through the process at several units, and we also share our ideas about contents and presentation.

\section{General principles}

Above all, the handbook should be useful and practical. Experience has shown a convenient 'pocket-size' (such as A5) is best, although a larger A4 book is perhaps less easily mislaid and has a more impressive look. Brevity is essential, and while a comprehensive tome may seem most informative, realistically it is unlikely to be read. Topics covered in standard textbooks are therefore best avoided, although a 'recommended reading list' is easily added.

A cheery, user-friendly style is also important, with information presented in an advisory rather than dictatorial style. If particular rules and regulations are required to be set out, an appendix of policies and related matters such as audit standards can be included. This maintains the sympathetic approach.

A contents page is valuable, and we advocate large print, broad margins and double spacing to ease reading. Single-side typing, with a new page for each section, while less economic in paper, also helps. An authoritative print style lends a professional feel and using a plastic binder makes the whole more durable.

The information should be as static as possible, so that alterations to the document need be made only rarely. Data which frequently change are best avoided. Wherever possible we feel these books should be circulated prior to start days to allow trainees to assimilate some of the information.

\section{Contents}

Local circumstances will to an extent dictate contents, but the following are suggested as useful.

\section{Introduction}

A brief page of general information, perhaps including bed numbers, overview of catchment areas and an encouraging welcome ("we hope you find your time here useful ..." etc.). Day hospitals, community facilities and other places trainees may have contact with should be mentioned. The psychiatric tutor for the unit can be identified, and perhaps a list of the consultants with their special interests/ research work.

\section{Wards}

A list of the ward names, the patients they take, the consultants who admit to them, and the name of the ward manager(s).

\section{General responsibilities}

Details of how many consultants each junior will work for, their general ward duties and other duties, such as day hospital attendance. Only broad terms should be used, as details (e.g. clinic attendance) can be given with timetables. Access to community work and chances to visit community facilities might be included.

\section{Admission procedures}

Accepted standards for psychiatric assessment and physical examination. Advice on expected baseline investigations.

\section{On-call arrangements}

Rotas, who is responsible for their production. whereabouts of on-call room(s) and facilities, arrangements for keys, on-call duties (especially important if a two-tier system operates), requirements for residency, responsibilities under section 5 (2) Mental Health Act 1983.

\section{Daytime cover}

Details of casualty and liaison work (if any) and rotas. Location of a 'safe' room for interviewing in Casualty.

\section{Bleeps}

Where they are obtained and how they work.

\section{Timetables}

While some consultants seem reluctant, in general provision of the consultants' timetables are most useful as they change little and allow the trainee to know where their leader is. Beneath each timetable can be given the consultant's individual requirements, and also details of multidisciplinary team members (CPNs, OTs, psychologists, social workers etc.) and their whereabouts. Also, importantly, the secretary.

\section{Academic programme}

The time and place of journal clubs, case conferences, personal tuition and other 
teaching slots, including psychotherapy supervision and joint meetings with other specialties (e.g. grand round). Details of local MRCPsych and similar courses. The location of an overhead projector and acetates/pens/ video equipment or other visual aids for presenters.

\section{Library facilities}

Local and regional (e.g. university) with a list of journals and databases.

\section{Audit}

Timetable of meetings, and details of trainee's expected degree of involvement. Audit standards should have their own appendix.

\section{Administration}

Responsibilities for discharge letters, referrals and other correspondence. Expectations of time allowed for their completion.

\section{Absences from work \\ Local requirements of whom to inform about holidays, sick leave and study leave, and responsibilities for cover.}

\section{Electroconvulsive therapy}

Place, times, frequency, duties (i.e. administering, preparing the patient, whereabouts of anaesthetist etc.) and consultant responsible.

\section{Other information}

This may include teaching duties, opportunities for research, phlebotomy services, cardiac arrest arrangements, business meetings and other local idiosyncratic information.

\section{Appendices}

The advantage of an appendix is that it allows important information to have its own section

Copies of introductory handbooks of this style written by the authors are avallable on request from Dr Barnes. while not interrupting the gentler flow of the main text.

Useful appendices might include:

(a) plan of the site-essential for large hospital

(b) audit standards

(c) seclusion policy-including policies prohibiting seclusion

(d) other (local) policies

(e) useful telephone numbers

(f) whereabouts of services - including the canteen!

(g) rotas - at least the first month

(h) catchment areas - either a map or a street-listing

(i) advice on personal safety.

\section{Conclusion}

It is important that the handbook is comprehensive yet not too unwieldy. This ensures that it is likely to be read and reduces cost and preparation time. Attention to writing style will ensure brevity and clarity. If it is reasonably comprehensive, and the information fairly static, it is useful to provide a copy for the on-call room in case trainees neglectfully mislay their copy.

By providing such a handbook a department can assimilate new trainees into its particular way of working quickly and make life easier for them. This helps to make the biannual transition period less disruptive, and may help to enhance the status of the unit and even its popularity among junior staff.

\section{Reference}

SLATFORD, K. (1994) Organising induction courses in psychiatry. Psychiatric Bulletin. 18, 83-85.

*Richard C. Barnes, Senior Registrar in Old Age Psychiatry, Whiston Hospital, Dragon Lane, Prescot, Merseyside L35 5DR; and Stephen M. Earnshaw, Senior Registrar in Child and Adolescent Psychiatry. Child and Family Advisory Service, Thorn Road Clinic, Runcorn, Cheshire

*Correspondence 